\title{
Circumventing Pericyclic Reactions to Realize Insertion Polymerization of Cyclobutene Derivatives.
}

\author{
Keitaro Seto and Bruce M. Novak \\ Department of chemistry, North Carolina State University, \\ Raleigh, NC 27695, US. \\ novak@chemdept.chem.ncsu.edu \\ Supporting information
}

\section{Experimental Section}

General Procedures and Characterization

1,5-Cyclooctadiene, potassium tert-butoxide, acetophenone, 1,3-cycloheptadiene, 1,2bis(phenylphosphino)-ethane, 3-tertbutylsalicylaldehyde, aniline, glyoxal, 2,6-diisopropylaniline, 2,6diacetylpyridine, n-butyllithium, methylaluminoxane (MAO), tiisobutylaluminum and were purchased from Aldrich Chemical Inc. and used as received. Pentafluorophenol was purchased from Tokyo Kasei Ltd. Nickel(II) chloride hexahydrate, (COD) $\mathrm{PdCl}_{2}$, iron(II) chloride tetrahydrate, zirconium(IV) chloride tetrahydrofranate, nickel(II) acetylacetonato, bis(cyclooctadiene) nickel and zirconium monocyclopentadiene trichloride were purchased from Strem Chemicals Inc. and used as received except for nickel(II) acetylacetonato, which was recrystallized from benzene solution. Tris(pentafluorophenyl) borane and triphenylmethyl tetrakis(pentafluorophenyl) borate were provided from Albemarle Corp. Water was purified through reverse osmosis filter.

Toluene, hexane, benzene, dichloromethane, and diethylether were purchased from Aldrich Chemical Inc. as anhydrous grade and used passing through Mbraun dry solvent system. Other solvents were purchased from Aldrich Chemical Inc. or Fisher Scientific with or without standard purification as 
needed. In the case of handling the air/moisture sensitive materials, Mbraun Unilab Dry-Box system was used as needed.

${ }^{1}$ H-NMR spectra were obtained using a Varian Mercury 400 (400 MHz), Varian Mercury 300 (300 $\mathrm{MHz})$ spectrometers, or Bruker AVANCE $500(500 \mathrm{MHz})$ as specified. Chemical shifts are reported in $\delta(\mathrm{ppm})$ and are referenced to selected residual proton peaks for the solvents or to internal standard. Significant ${ }^{1} \mathrm{H}$ NMR data are tabulated in the following order: chemical shift, multiplicity $(\mathrm{s}=$ singlet, $\mathrm{d}$ = doublet, $\mathrm{t}=$ triplet, $\mathrm{q}=$ quartet, $\mathrm{m}=$ multiplet, br: broad), coupling constant in Hertz, number of protons.

The gel permeation chromatography was performed using 2 PL gel Mixed B columns and evaporative light scattering detector (ELSD) in trichlorobenzene at $160{ }^{\circ} \mathrm{C}$. All samples were prepared at approximate concentrations of $2 \mathrm{mg} / \mathrm{mL}$ in HPLC grade 1,2,4-Trichlorobenzene (TCB). The samples were shaken at $160^{\circ} \mathrm{C}$ to dissolve the polymer sample. All samples appeared to be soluble after overnight shaking. All samples were filtered through a $2 \mu \mathrm{m}$ stainless steel frit filter. Polystyrene standard was used for reference.

Differential scanning calorimetry and thermogravimetric analysis were performed using TA instrument systems model DSC 2920 and Hi-Res TGA 2950.

Procedures

Monomer synthesis : 1,3-Cyclooctadiene was prepared from 1,5-cyclooctadiene according to literature procedures. ${ }^{1}$

Bicyclo[4.2.0]oct-7-ene, 1 was prepared according to literature procedures. ${ }^{2}$

Bicyclo[3.2.0]hept-6-ene, 2 was prepared according to literature procedures. ${ }^{3}$

Catalyst synthesis : [1,2-bis(diphenylphosphino)ethane]dichloronickel(II) was prepared according 
to literature procedures. ${ }^{4}$

\section{[ $N$-(3-tert-butylsalicylidene)-anilinato]-phenyl-triphenylphosphine nickel(II) was synthesized} modified procedure from literatures. ${ }^{5,6}$ (a) Ligand synthesis. To a stirred solution of 3tertbutylsalicylaldehyde $(3.2 \mathrm{~g}, 18.0 \mathrm{mmol})$ in ethanol $(5 \mathrm{~mL})$, a solution of aniline $(2.2 \mathrm{~g}, 23.6 \mathrm{mmol})$ in ethanol $(10 \mathrm{~mL})$ was added dropwise over a 5 minutes period at room temperature. The mixture was stirred for 24 hours and reaction mixture was concentrated in vacuo to afford a crude imine compound. Purification by column chromatography on silica gel using hexane/ethyl acetate (10/1) as eluent gave $N$ (3-tert-butylsalicylidene) aniline $(3.9 \mathrm{~g}, 15.4 \mathrm{mmol})$ as a yellow oil in $86 \%$ yield. ${ }^{1} \mathrm{H}-\mathrm{NMR}(400 \mathrm{MHz}$, $\left.\mathrm{CDCl}_{3}\right): \quad \delta 8.63(\mathrm{~s}, 1 \mathrm{H}), 7.44-6.86(\mathrm{~m}, 8 \mathrm{H}), 1.47(\mathrm{~s}, 9 \mathrm{H}):$ (b) Complex synthesis. (trans $\left[\mathrm{NiCl}(\mathrm{Ph})\left(\mathrm{PPh}_{3}\right)\right]$ was prepared from $\mathrm{Ni}\left(\mathrm{PPh}_{3}\right)_{4}$ and chlorobenezene.) To a stirred suspension of sodium hydride $(82.8 \mathrm{mg}, 3.45 \mathrm{mmol})$ in THF, at room temperature solution of $\mathrm{N}$-(3-tertbutylsalicylidene) aniline $(0.38 \mathrm{~g}, 1.5 \mathrm{mmol})$ in THF $(15 \mathrm{~mL})$ was added dropwise over a 5 minutes period. The solution was stirred for $2 \mathrm{~h}$. The resulting solution was filtered to remove excess sodium hydride. After evaporating the solvent, sodium salt solid was formed. $25 \mathrm{~mL}$ of benzene and $\operatorname{trans}\left[\mathrm{NiCl}(\mathrm{Ph})\left(\mathrm{PPh}_{3}\right)\right](1.0 \mathrm{~g}, 1.43 \mathrm{mmol})$ was added to this sodium saltas. The mixture was stirred for 24 hours. After filtration, solvent was evaporated. The solid was recrystallized from a pentane solution at $-40{ }^{\circ} \mathrm{C}$ to give a target complex $(0.33 \mathrm{~g}, 0.5 \mathrm{mmol})$ as orange crystal in $34 \%$ yield. ${ }^{1} \mathrm{H}-\mathrm{NMR}$ (300MHz, $\left.\mathrm{C}_{6} \mathrm{D}_{6}\right): \delta 6.20-7.84(\mathrm{~m}, 28 \mathrm{H}), 0.91(\mathrm{~s}, 9 \mathrm{H})$

$[(\mathbf{A r N}=\mathbf{C}(\mathbf{H})-\mathbf{C}(\mathbf{H})=\mathbf{N A r})] \mathbf{P d}\left(\mathbf{C H}_{3}\right) \mathbf{C l}$ was prepared according to literature procedures. ${ }^{7}$

2,6-bis-[1-(2,6-dimethylphenylimino)ethyl]pyridine iron(II)chroride was prepared according to literature procedures. ${ }^{8}$

Bis[N-(3-tert-butylsalicylidene)anilinato]zirconium(IV) dichloride was prepared according to literature procedures. ${ }^{5}$ 
Polymerization procedure in Table 1: All manipulations are under nitrogen using standard Schlenk techniques in a dry-box.

Run 1 : Bis[N-(3-tert-butylsalicylidene)anilinato]zirconium(IV) dichloride (1 mL of $10.0 \mu \mathrm{mol} / \mathrm{mL}$ solution in toluene) was placed in Schlenk flask, then MAO 1.7 M solution in toluene of $20 \mathrm{~mL}$ was added at room temperature. $1.0 \mathrm{~g}(9.24 \mathrm{mmol})$ of monomer 1 was added to this solution. After 24 hours of stirring at room temperature, the resulting hazy solution was poured into acidic methanol. The polymeric product was then washed, filtered and dried under vacuum. $0.64 \mathrm{~g}$ of poly-1 was obtained as white powder. $\left(64 \%\right.$ yield) High temperature $\left(130^{\circ} \mathrm{C}\right) \mathrm{GPC}$ analysis : $\mathrm{Mw}=3,300, \mathrm{Mn}=1,100$

Run 2 : MAO 1.7 M solution in toluene of $3 \mathrm{~mL}$ was placed in Schlenk flask, and then bis[N-(3-tertbutylsalicylidene)anilinato]zirconium (IV) dichloride ( $1 \mathrm{~mL}$ of $10.0 \mu \mathrm{mol} / \mathrm{mL}$ solution in toluene) was then added at room temperature. $1.0 \mathrm{~g}(9.24 \mathrm{mmol})$ of monomer $\mathbf{1}$ was added to this solution. After 18 hours of stirring at room temperature, the hazy solution was poured into acidic methanol. The polymeric product was then washed, filtered and dried under vacuum. $0.97 \mathrm{~g}$ of poly-1 was obtained as white powder. $\left(97 \%\right.$ yield) High temperature $\left(130^{\circ} \mathrm{C}\right) \mathrm{GPC}$ analysis : $\mathrm{Mw}=219,000, \mathrm{Mn}=141,000$

Run $3^{9}$ : MAO 1.7 M solution in toluene of $3 \mathrm{~mL}$ was placed in Schlenk flask, then solvent and volatile trimethylalminum were removed by 4 hours of vacuum. $3 \mathrm{~mL}$ of toluene was added to dissolve “dried” MAO, and bis[N-(3-tert-butylsalicylidene)anilinato]zirconium(IV) dichloride (1 mL of 10.0 $\mu \mathrm{mol} / \mathrm{mL}$ solution in toluene) was then added at room temperature. Monomer 1 (1.0 g, $9.24 \mathrm{mmol})$ solution in $6 \mathrm{~mL}$ of toluene was added to this solution. After 18 hours of stirring at room temperature, the hazy solution was poured into acidic methanol. The polymeric product was then washed, filtered and dried under vacuum. $0.83 \mathrm{~g}$ of poly-1 was obtained as white powder. (83\% yield) High temperature $\left(130^{\circ} \mathrm{C}\right) \mathrm{GPC}$ analysis : $\mathrm{Mw}=164,000, \mathrm{Mn}=99,000$

Run $4^{10}$ : MAO 1.7 M solution in toluene of $3 \mathrm{~mL}$ was placed in Schlenk flask, then $18 \mu \mathrm{L}$ of water was added to MAO solution and kept stirring for 10 minutes at room temperature. $0.84 \mathrm{~g}$ of 
pentafluorophenol in $3 \mathrm{~mL}$ of toluene was added and stirred for another 10 minutes. Bis[N-(3-tertbutylsalicylidene)anilinato]zirconium(IV) dichloride (1 mL of $10.0 \mu \mathrm{mol} / \mathrm{mL}$ solution in toluene) was then added to this solution followed by monomer $1(1.0 \mathrm{~g}, 9.24 \mathrm{mmol})$ solution in $3 \mathrm{~mL}$ of toluene was added to this solution. After 20 hours of stirring at room temperature, the hazy solution was poured into acidic methanol. The polymeric product was then washed, filtered and dried under vacuum. $0.9 \mathrm{~g}$ of poly-1 was obtained as white powder. (90\% yield) High temperature $\left(130^{\circ} \mathrm{C}\right) \mathrm{GPC}$ analysis : Mw = 7,400, $\mathrm{Mn}=2,100$

Run $5^{11}$ : Triisobutylaluminum solution in toluene $(1.0 \mathrm{M})$ of $1 \mathrm{~mL}$ was placed in schlenk flask. $3 \mathrm{~mL}$ of toluene was added to this solutin followed by bis[ $N$-(3-tert-butylsalicylidene)anilinato]zirconium(IV) dichloride $(1 \mathrm{~mL}$ of $10.0 \mu \mathrm{mol} / \mathrm{mL}$ solution in toluene). After 10 minutes of stirring at room temperature, $18.5 \mathrm{mg}$ of triphenylmethyl tetrakis(pentafluorophenyl) borate in $2 \mathrm{~mL}$ of toluene was added, then monomer $1(1.0 \mathrm{~g}, 9.24 \mathrm{mmol})$ solution in $3 \mathrm{~mL}$ of toluene was added. After 20 hours of stirring at room temperature, the hazy solution was poured into acidic methanol. The polymeric product was then washed, filtered and dried under vacuum. $0.14 \mathrm{~g}$ of poly-1 was obtained as white powder. (14 $\%$ yield) High temperature $\left(130^{\circ} \mathrm{C}\right) \mathrm{GPC}$ analysis $: \mathrm{Mw}=2,400, \mathrm{Mn}=700$

Run $6^{9}: 0.42 \mathrm{~mL}$ of trioctylaluminum hexane solution $(0.48 \mathrm{M})$ was placed in schlenk flask and hexane was removed under vacuum. After an addition of $4 \mathrm{~mL}$ of toluene, bis[N-(3-tertbutylsalicylidene)anilinato]zirconium(IV) dichloride (1 $\mathrm{mL}$ of $10.0 \mu \mathrm{mol} / \mathrm{mL}$ solution in toluene) was added. $5.12 \mathrm{mg}$ of tris(pentafluorophenyl) borane in $3 \mathrm{~mL}$ of toluene was added, follwed by addition of monomer $1(1.0 \mathrm{~g}, 9.24 \mathrm{mmol})$ solution in $3 \mathrm{~mL}$ of toluene. After 18 hours of stirring at room temperature, the hazy solution was poured into acidic methanol. Only a trace amount of polymeric material was obtained.

Run 7 : At room temperature, $1.5 \mathrm{~mL}$ of triisobutylaluminum solution in toluene $(1.0 \mathrm{M})$ and $27 \mu \mathrm{L}$ of water were reacted in Schelnk flask with $2 \mathrm{~mL}$ of toluene. To this flask, $2.1 \mathrm{~mL}$ of MAO toluene 
solution (1.7M) was added. Toluene solution of bis[ $N$-(3-tert-butylsalicylidene)anilinato]zirconium(IV) dichloride ( $1 \mathrm{~mL}$ of $10.0 \mu \mathrm{mol} / \mathrm{mL}$ solution in toluene) was added, then monomer $\mathbf{1}$ ( $1.0 \mathrm{~g}, 9.24 \mathrm{mmol})$ in $3.5 \mathrm{~mL}$ of toluene was added. After 22 hours of stirring at room temperature, the hazy solution was poured into acidic methanol. The polymeric product was then washed, filtered and dried under vacuum. $0.86 \mathrm{~g}$ of poly-1 was obtained as white powder. (86 \% yield) High temperature $\left(130^{\circ} \mathrm{C}\right) \mathrm{GPC}$ analysis : $\mathrm{Mw}=245,000, \mathrm{Mn}=155,000$

Polymerization of monomer 2 was performed same procedure as corresponding monomer 1 polymerization.

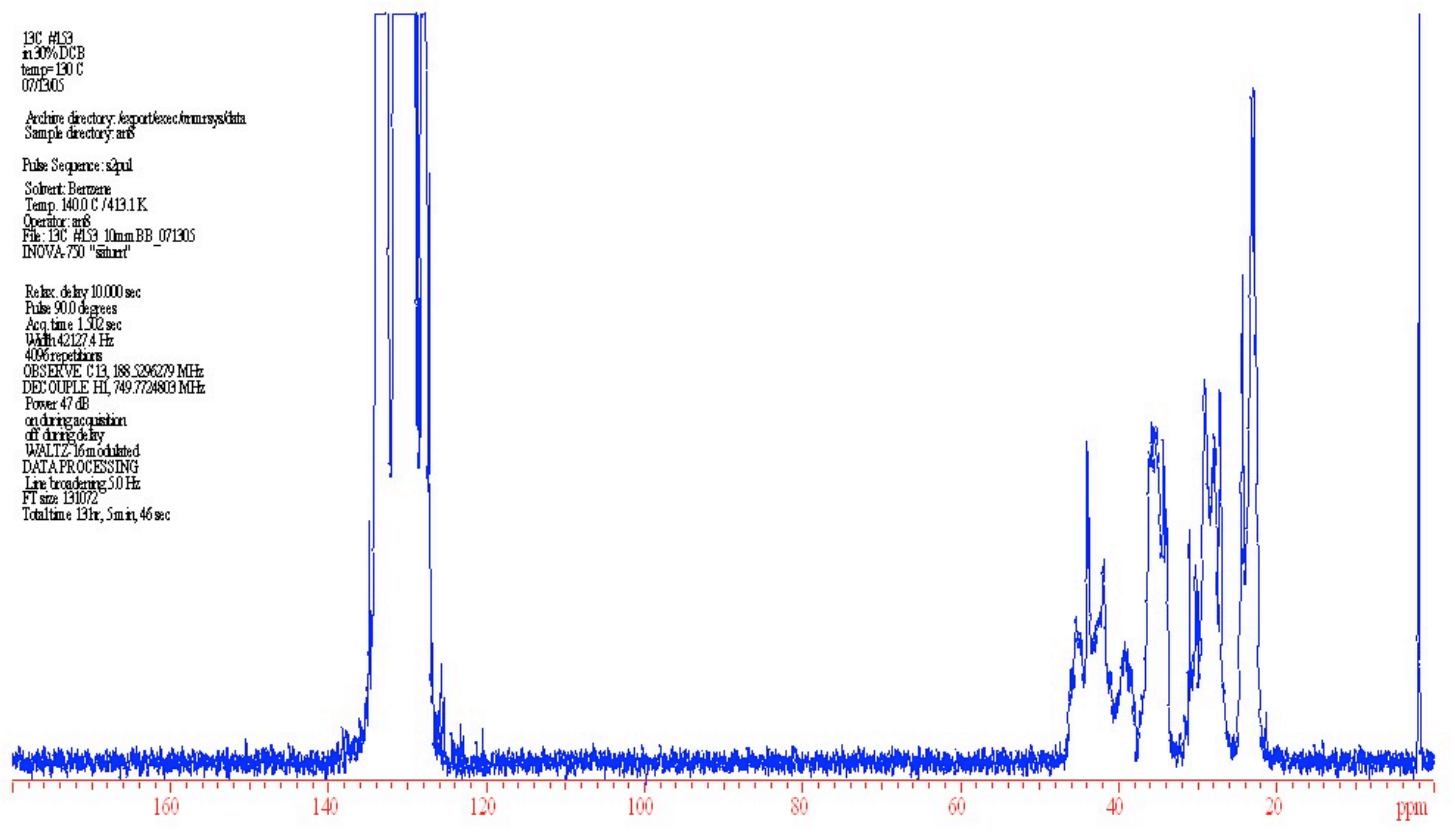

Figure 1. 13C-NMR spectrum of poly-1 in $o-\mathrm{DCB}$ at $130{ }^{\circ} \mathrm{C}$ 


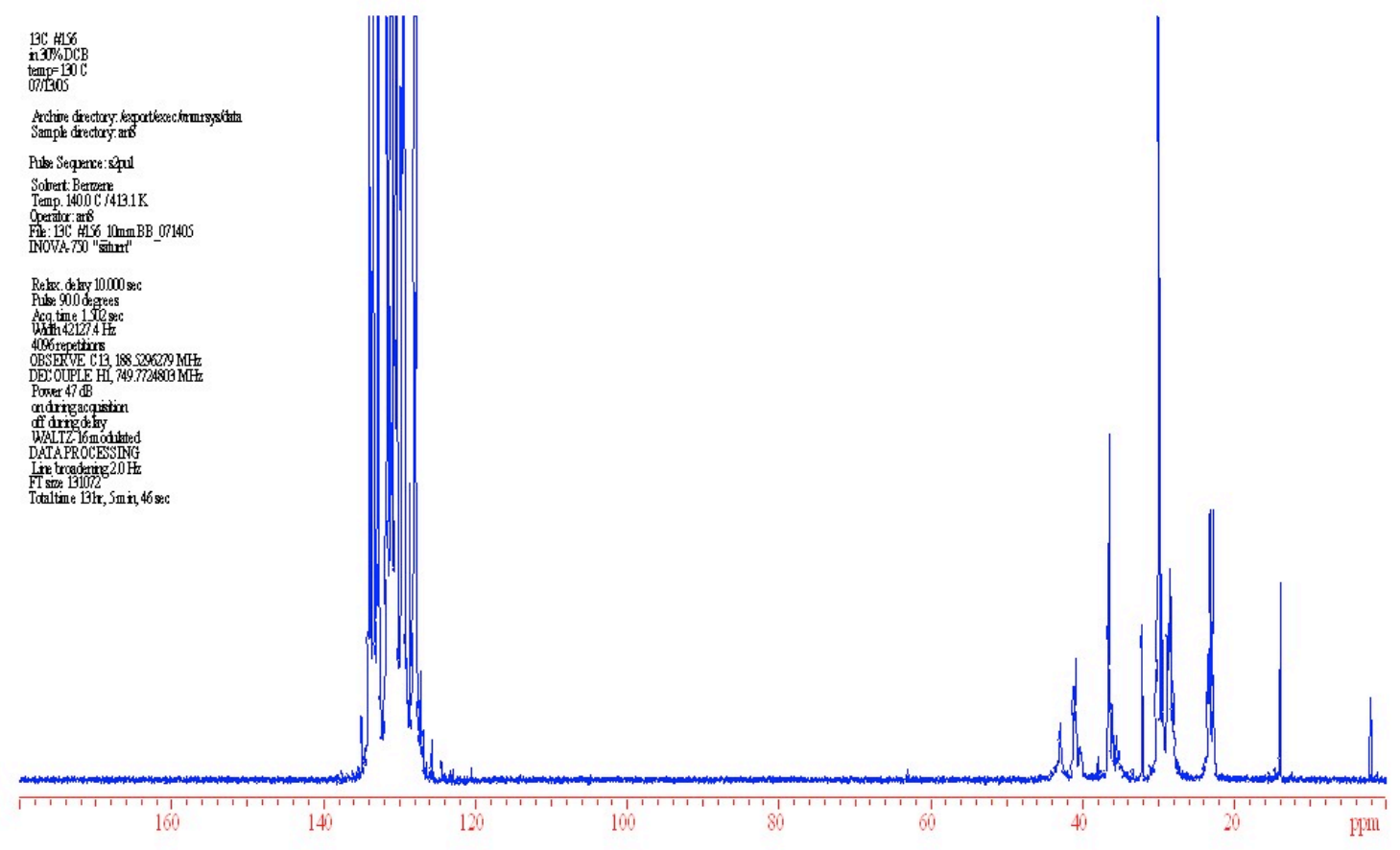

Figure 2. ${ }^{13} \mathrm{C}-\mathrm{NMR}$ spectrum of poly $(\mathbf{1}-\mathrm{co}-\mathrm{E})$ in $o$-DCB at $130{ }^{\circ} \mathrm{C}$

\section{References}

1. Evaprabhakara, D.; Cardenas, C.; Gardner, P. D. J. Am. Chem. Soc. 1963, 85, 1553.

2. $\quad$ Liu, R. S. H. J. Am. Chem. Soc. 1967, 89, 112.

3. Inoue, Y.; Hagiwara, S.; Daino, Y.; Hakushi, T. J . Chem. Soc., Chem. Commun., 1985, 1307.

4. Busby, R.; Hursthouse, M. B.; Jarrett, P. S.; Lehrnann, C. W.; Malik, K. M. A.; Phillips, C. J. Chem. Soc. Dalton Trans. 1993, 3767.

5. Matsui, S.; Mitani, M.; Saito, J.; Tohi, Y.; Makio, H.; Matsukawa, N.; Takagi, Y.; Tsuru, K.; Nitabaru, M.; Nakano, T.; Tanaka, H.; Kashiwa, N.; Fujita, T. Journal of the American Chemical Society 2001, 123, (28), 6847-6856. 
6. Wang, C.; Friedrich, S.; Younkin, T. R.; Li, R. T.; Grubbs, R. H.; Bansleben, D. A.; Day, M. W. Organometallics 2001, 17, 3149.

7. Johnson, L. K.; Killian, C. M.; Brookhart, M. Journal of the American Chemical Society 1995, $117,(23), 6414-15$.

8. Small, B. L.; Brookhart, M.; Bennett, A. M. A. Journal of the American Chemical Society 1998, 120, (16), 4049-4050.

9. Ioku, A.; Hasan, T.; Shiono, T.; Ikeda, T. Macromol. Chem. Phys. 2002, 203, 748.

10. Fujita, M.; Seki, Y.; Miyatake, T. Macromol. Chem. Phys. 2004, 205, 884.

11. Saito, J.; Mitani, M.; Matsui, S.; Tohi, Y.; Makio, H.; Nakano, T.; Tanaka, H.; Kashiwa, N.; Fujita, T. Macromolecular Chemistry and Physics 2002, 203, (1), 59-65. 